\title{
Prof Torben Lorentzen, EFSUMB Publication Committee talked to Prof Diana Gaitini about the 2014 EUROSON Congress.
}

'It is my great pleasure to invite you to the 26th EUROSON Congress, hosted by EFS$\mathrm{UMB}$ and the Israel Society for Diagnostic Ultrasound in Medicine (ISDUM) to be held on 25-28 May, 2014 in Tel Aviv, Israel. Almost 25 years have passed since the $7^{\text {th }}$ EUROSON Congress which took place in Jerusalem, Israel.

EUROSON 2014 will bring together leading physicians in the field of ultrasound to share their knowledge and experience and discuss the current state and the direction ultrasound may take in the upcoming years. The meeting will bring the latest developments in ultrasound technology, clinical applications and practice through a comprehensive program of precongress courses, special lectures, symposiums, scientific presentations, poster sessions and technical exhibition. Topics of ultrasound relating to the fields of abdomen, musculoskeletal, interventional, small parts, breast, new technologies, paediatrics, urology, anaesthesiology and emergency medicine, vascular, gynecoobstetric and others will be included. Participants will be able to enhance their practical knowledge and skills through hands-on workshops and training sessions. Visit the website www.euroson2014. org for all the information.
EUROSON 2014 will be held at the David Intercontinental Hotel, located on the beachfront promenade and neighbouring the ancient port city of Jaffa, a step away from Neve Tzedek, Israel's largest open-air market and Tel Aviv's oldest and most fashionable neighbourhood. Tel Aviv is Israel's largest city and commercial centre, located along the beautiful Mediterranean coastline, known for its distinctive Bauhaus architecture. This busy metropolis invigorates visitors with a unique energetic atmosphere, outstanding museums, cultural events, international cuisine, and non-stop active nightlife.

Israel not only boasts a culture rich in history but also a diverse heritage and a capital city sacred to all three monotheistic religions: Judaism, Christianity and Islam. EUROSON 2014 gives you an opportunity to visit unique historical sites and wonderful sightseeing like the Dead Sea and Masada, Jerusalem, the Galilee Sea, where much of the early ministry of Jesus occurred, Eilat on the Red Sea and many other places. Please visit the congress website for further tourist information.

We look forward to welcoming you to EUROSON 2014 in Tel Aviv.'

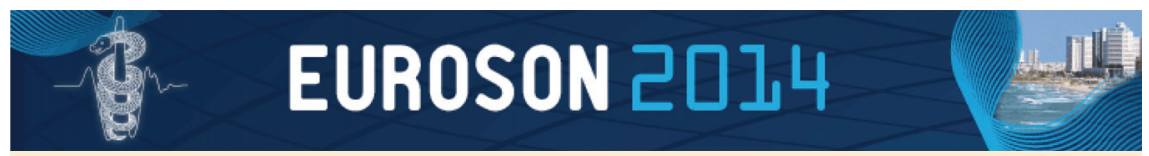

TEL AVIV, ISRAEL

25 - 28 May 2014 